\title{
Effect of Polymer Adhesive Film Supplemented 5\% NaF on Enamel Remineralization
}

\author{
Myeongkwan Jih, Sangho Lee, Nanyoung Lee \\ Department of Pediatric Dentistry, College of Dentistry, Chosun University
}

\section{Abstract}

This study was designed to evaluate the effectiveness of $5 \%$ sodium fluoride-polyvinyl alcohol (NaF-PVA) tape influencing enamel remineralization by analysing enamel surface microhardness (SMH) and variation of $\Delta \mathrm{F}$ of QLF.

After enamel demineralizing of specimen, these 60 specimens with average KHN of microhardness ranging from 50 to 100 and with $\triangle \mathrm{F}$ of QLF ranging from -15 to -25 were divided into four groups : group 1 (control group), group 2 (NaF-PVA), group 3 (fluoride varnish, FluoroDose ${ }^{\circledR}$ varnish), group 4 (Casein phosphopeptideamorphous calcium phosphate, Tooth mousse plus $\left.{ }^{\mathrm{TM}}\right)$. These specimens were treated with materials and then immersed in artificial saliva. We measured remineralization rate each using surface microhardness (SMH) and Quantitative light-induced fluorescence digital (QLF-D).

As a result, NaF-PVA tape is better than group 1, 4 and have comparable remineralization effect with group 3 $(p<0.05)$.

Key words : Sodium fluoride-polyvinyl alcohol, Remineralization, Quantitative light-induced fluorescence

\section{I. 서 론}

최근 치과계의 치아우식증 치료에 대한 인식의 변화가 뚜렷 해지고 있다. 과거의 수복, 보철적인 치료에서 그 이전 단계인 조기진단, 예방으로의 패러다임의 변화는 임상의들에게 많은 변화를 요구하고 있다 ${ }^{1-4)}$. 초기 우식병소는 여러 가지 방법으로 다시 재광화 될 수 있는 것으로 알려져 있닫. 따라서 재광화의 역할이 우식의 조기치료로서 중요시되고 있다.

불소는 현재까지 정립된 가장 이상적인 재광화 제제라고 할 수 있다 ${ }^{6}$. 이런 불소를 이용한 우식 예방법에는 불화된 상수도 수를 섭취하는 방법과 불소 보조제를 복용하는 방법, 불소치약, 불소양치액 그리고 전문가 불소도포법이 있닥. 전문가 국소도 포용으로 많이 사용되고 있는 제제인 불소바니쉬는 그 효율성 과 안정성이 입증되었으나 도포시 치아의 일시적 착색과 씁쓸
한 맛, 끈적끈적한 질감으로 인해 어린이 및 청소년에게 거부감 을 갖게 한다. 또한 불소바니쉬는 치면에 오래 붙어있지 않고 타액이나 저작, 잇솔질 등에 의해 쉽게 씻겨져 내려가므로 구강 내에서 적절한 불소농도를 오랫동안 유지해 줄 수 없다는 점이 문제점으로 제기되고 있달.

이와 같은 문제점을 해결하기 위해 새로운 불소전달시스템에 대한 연구가 많이 진행되어왔다. Toumba와 Curzon'은 녹는 glass에 불소를 결합시킨 완속유리제제를 개발하여 구강 내에 부착하는 장치를 고안하였으며 Marini 등 ${ }^{10)}$ 은 hydroxyethyl methacrylate (HEMA) / methyl methacrylate (MMA) 공 중합체를 이용하여 최장 180 일 동안 불소를 유리할 수 있는 장 치를 고안하였다. 그러나 이러한 완속유리제제의 문제점은 용 기의 부피로 인해 이물감이 크며 치아로부터 자주 탈락이 된다 는 것이다. 또한 불소농도의 조절이 용이하지 않아 장기간에 걸

\footnotetext{
Corresponding author : Sangho Lee

Department of Pediatric Dentistry, College of Dentistry, Chosun University, 375 Seosuk-Dong, Dong-Gu, Gwangju, 501-759, Korea

Tel: +82-62-220-3865 / Fax: +82-62-225-8240 / E-mail: shclee@chosun.ac.kr

Received March 13, 2014 / Revised July 18, 2014 / Accepted July 25, 2014

※ This study was supported by research fund from Chosun University, 2014.
} 
쳐 과량의 불소가 공급될 수 있다는 문제점이 있다.

최근에는 고분자 필름에 불소를 첨가하여 치아에 접착하는 도포방법이 제시되고 있다. 고분자 제제의 하나인 Polyvinyl alcohol (PVA)는 섬유코팅, 접착, 필름 제조 등 산업 전반에 걸쳐 사용되고 있는 소재로 의학 분야에서는 인공장기의 원료 가 되는 하이드로젤 (hydrogel), 약물 전달 시스템, 바이오센서 (biosensor), 바이오리엑터(bioreactor) 등의 제조에 활용되고 있다 ${ }^{11}$

$\mathrm{Kim}$ 등 ${ }^{12)}$ 은 PVA 테잎에 불소를 첨가한 접착테잎 $(\mathrm{NaF}-$ PVA)을 사용하여 치아 탈회억제 효과를 비교한 결과, NaFPVA 테잎은 $\mathrm{CPP}-\mathrm{ACFP}$ 보다 우수하며 불소 바니쉬와 견줄만 한 탈회 방지 효과를 보였다고 보고하였으며 Lee 등히는 $\mathrm{NaF}-$ PVA 테잎의 치아 지각과민 처치제로서의 효능을 시험한 결과, 다른 불소바니쉬 제제에 비해 4 주, 8 주 후에 더 효과가 좋다고 보고하였다.

법랑질 재광화 효과를 측정하기 위한 방법들로 표면미세경도 측정, $\mathrm{SEM}$ 등이 제시되고 있으며 최근에는 비침습적인 $\mathrm{QLF}$ (Quantitative light-induced fluorescence)가 이를 측정하는 데 사용되고 있다 ${ }^{14-16)}$

$\mathrm{QLF}$ 는 치아우식증을 발견하고자 하는 노력에 의해 치아우식 증의 조기진단 도구(tool)로서 개발되었다 ${ }^{17)} . \mathrm{QLF}$ 는 $405 \mathrm{~nm}$ 의 파장을 가지고 있는 푸른색의 가시광선을 이용한 도구이다. 이 빛을 치아에 조사하면 건전한 치아의 경우 빛이 상아-법랑질 경계(Dentino-enamel junction)까지 투과한 뒤 반사되면서 녹색의 자연형광이 발생하게 된다. 그러나 탈회 부위의 경우, 병소 부위에서 빛이 산란되면서 형광이 소실되어 검게 보인다. $\mathrm{QLF}$ 는 이렇게 형광이 소실된 정도를 정량화시켜서 구체적인 수치로 제시할 수 있다.

불소함유 필름은 무색, 무취, 무미의 생체 친화적 제제로 이 전의 연구들 ${ }^{12,13)}$ 에 근거할 때 치아에 접착력이 좋으며 오랫동안 유지되어 불소의 방출이 장기간에 걸쳐 서서히 이루어지므로 향후 새로운 불소제제의 형태로 활용성이 높다고 판단된다. 이 전의 연구 ${ }^{12}$ 에서 $\mathrm{NaF}-\mathrm{PVA}$ 테잎의 불소방출 능력에 따른 탈회 방지 효과는 입증되었지만 정량화된 더 많은 연구가 필요하다 고 생각되었다. 따라서 본 연구는 실험실상에서 $\mathrm{NaF}-\mathrm{PVA}$ 를 표면미세경도계와 $\mathrm{QLF}-\mathrm{D}$ 를 이용하여 다른 불소제제들과 비교 함으로써 NaF-PVA 테잎의 재광화 효과를 평가하고자 하였다.

\section{II. 연구 재료 및 방법}

\section{1. 연구 재료}

1) 시편

발거된 소의 절치 중 치아우식이 없고, 건전한 법랑질 표면을 갖는 치아를 대상으로 시편을 제작하였다. 소의 절치를 저속핸 드피스로 $5 \mathrm{~mm} \times 5 \mathrm{~mm} \times 5 \mathrm{~mm}$ 의 크기로 절단한 후 미리 제작된 아크릴 주형에 매몰하였다. 총 100 개의 시편이 제작되 었으며 매몰된 시편을 silicon carbamide paper를 이용하여

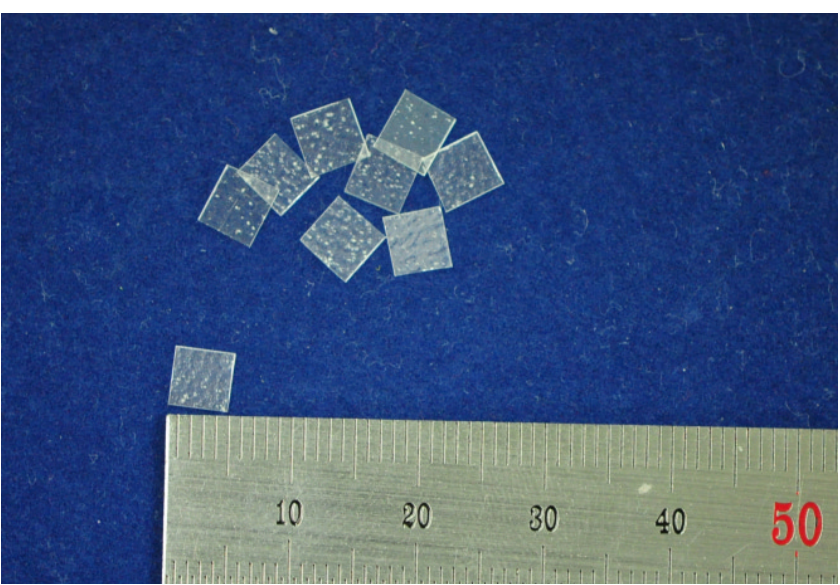

Fig. 1. 5\% sodium fluoride-polyvinyl alcohol tape.

400, 800, 2400 그리고 4000 grit까지 단계적으로 연마하였 다. 연마 후 시편 표면적의 $1 / 2$ 인 $2.5 \mathrm{~mm} \times 5 \mathrm{~mm}$ 에 nail varnish를 도포하였다.

\section{2) NaF-PVA 테잎}

본 연구에 사용한 $5 \% \mathrm{NaF}$ 함유 고분자 접착 필름 $\left(\mathrm{NaF}^{-}\right.$ PVA)은 기저제인 Polyvinyl alcohol (PVA)와 polyacrylic acid를 증류수에 용해시킨 후 가소제로서 polyethylene glycol 을 첨가하고, 여기에 $0.95 \mathrm{~g}$ 의 $\mathrm{NaF}$ 를 첨가하여 $2.26 \%$ 의 불소 를 함유하도록 제작하였으며 두께는 $20 \mu \mathrm{m}$ 이다(Fig. 1).

$\mathrm{NaF}-\mathrm{PVA}$ 의 재광화 능력을 비교, 평가하기 위해 시판되고 있는 Casein phosphopeptide-amorphous calcium fluoride phosphate (CPP-ACFP, GC Tooth mousse plus ${ }^{\mathrm{TM}}$, Recaldent, GC Corp., Japan)와 불소바니쉬인 FluoroDose ${ }^{\circledR}$ $(5 \% \mathrm{NaF}$, Centrix Inc., USA)를 이용하였다.

\section{2. 실험 방법}

1) 시편의 탈회

제작된 시편들을 이전의 문헌 ${ }^{18)}$ 을 참고하여 탈회 용액 〔2.2 $\mathrm{mM} \mathrm{Ca}\left(\mathrm{NO}_{3}\right)_{2}, 2.2 \mathrm{mM} \mathrm{KHxPO}_{4}, 50 \mathrm{mM}$ acetic acid, pH 4.5 ]에 $37^{\circ} \mathrm{C}$ 로 48 시간 동안 담구었다.

\section{2) 시편의 처치}

탈회한 시편들을 QLF-D ( QLF-D biluminator ${ }^{\mathrm{TM}}$, Inspektor Research systems BV, Amsterdam, The Netherlands)를 이용하여 탈회 정도를 정상 치질과 비교하여 수치적으로 나타낸 $\mathrm{Q}-\mathrm{ray}$ 값 $(\Delta \mathrm{F}$ 값)을 측정하고, 시편의 표면 미세경도(SMH, surface microhardness)를 표면미세경도계 (100 g, 5 s, HMV 2; Shimadzu Corporation, Tokyo, Japan)를 이용하여 KHN (Knoop Hardness Number)의 평 
균값을 측정하였다. 시편의 표면미세경도가 평균 $\mathrm{KHN}$ $50 \sim 110$ 의 범위를 갖고 $\mathrm{QLF}$ 의 $\Delta \mathrm{F}$ 값이 $-25 \sim-15$ 범위를 갖 는 60 개의 시편을 선택하였다. 이 시편들을 무작위로 15 개씩 4 개의 군으로 선택, 배분하였다. 불소 제제별 재광화 효과를 비 교하기 위해 각 그룹별로 다음과 같은 불소제제들이 사용되었 다.

(1) 대조군 : 시편에 어떤 제제도 적용하지 않은 상태로 인공 타액 (증류수 $+1.5 \mathrm{mM} \mathrm{Ca}\left(\mathrm{NO}_{3}\right)_{2} \cdot 4 \mathrm{H}_{2} \mathrm{O}+0.9 \mathrm{mM}$ $\mathrm{NaH}_{2} \mathrm{PO}_{4} \cdot 2 \mathrm{H}_{2} \mathrm{O}+150 \mathrm{mM} \mathrm{KCl}+0.1 \mathrm{mM}$ Tris buffer $+0.03 \mathrm{ppm} \mathrm{F}, \mathrm{pH} 7.0,37^{\circ} \mathrm{C}$ )에 7 일 동안 위 치시켰으며 6시간마다 교체하였다.

(2) $5 \% \mathrm{NaF}-\mathrm{PVA}$ 필름군 : 시편에 $2.5 \mathrm{~mm} \times 0.5 \mathrm{~mm}$ 크 기의 $\mathrm{NaF}-\mathrm{PVA}$ 필름을 환자의 실제 적용시간을 고려하 여 4분 동안 유지시켰다. 이 후 시편들을 인공타액에 담 구었다. 인공타액을 6 시간마다 교체하여 7일 동안 위치 시켰다.

(3) F-varnish군 : 각 시편의 탈회된 부분에 불소 바니쉬 (FluoroDose ${ }^{\circledR}$ Centrix Inc., USA)를 전용 어플리케이 터를 이용하여 환자의 구강내 적용하는 시간을 고려하여 4 분간 위치시켰다. 이 후 시편들을 NaF-PVA 테잎 군과 같은 방법으로 처리하였다.

(4) $\mathrm{CPP}-\mathrm{ACFP}$ 군 : 미세솔을 사용하여 CPP-ACFP (GC Tooth mousse plus ${ }^{\mathrm{TM}}$, Recaldent, GC Corp., Japan) 크림을 탈회부위에 적용하였다. 이후 시편들을 인공타액 에 위치시켰다. 제조사의 사용방법에 따라 하루에 두 번 씩 12 시간마다 같은 방법으로 적용하였으며 인공타액은 6시간마다 교체하여 7일동안 위치시켰다.

3) 표면미세경도 측정에 의한 시편의 재광화율

인공타액에 위치시킨 시편의 미세경도를 표면미세경도계를 이용하여 측정하고 이들의 평균값을 구하였다. 표면미세경도는 동일한 실험자가 측정하였다.

이후 다음과 같은 표면미세경도 측정값을 이용하여 재광화율 (Recovery percentage of surface microhardness)을 계산하 였다.

$\% \mathrm{SMR}=[\mathrm{KHN}$ (after remineralization) $-\mathrm{KHN}$ (before remineralization)) / KHN (before remineralization)] $\times$ $100 \%$

\section{4) QLF-D 측정에 의한 시편의 재광화율}

$\mathrm{QLF}$ 를 이용하여 시편들의 $\Delta \mathrm{F}$ 값을 동일한 실험자가 암실에 서 측정하였다. QLF-D 영상은 디지털 카메라(EOS-550D, Canon, Tokyo, Japan)로 셔터 스피드 $1 / 45$ 초, 조리개값 3.2 그리고 ISO 1600으로 설정하여 촬영하였다. 컴퓨터 자동 저장 소프트웨어로 C3 v1.18 (Inspektor Research System BV) 을 분석 프로그램으로 QA2 v1.18 (Inspektor Research System BV)을 사용하였다. 각 불소제제를 적용하였고 시편들 의 형태를 $99 \%$ 값으로 중첩(repositioning)하여 인공타액에
담근 후의 $\Delta \mathrm{F}$ 값을 구하였다. $\mathrm{QLF}-\mathrm{D}$ 로 측정한 $\Delta \mathrm{F}$ 값의 재광 화율(회복률)은 다음의 공식으로 구하였다.:

$\mathrm{R} \Delta \mathrm{F}[$ Recovery Percentage of $\Delta \mathrm{F}(\%)]=[(\Delta \mathrm{F}$ before remineralization $-\Delta \mathrm{F}$ after remineralization) $/ \Delta \mathrm{F}$ before remineralization] $\times 100 \%$

\section{5) 통계분석}

탈회와 재광화 정도를 윌콕슨 순위검정 (Wilcoxon matchedpairs signed ranks test)을 사용하여 분석하였다. 탈회 후 불 소도포 방법에 따른 군 간 타액 내 불소농도의 유의성 차이를 비교하기 위해 크루스칼-왈리스 검정 (Kruskal-Wallis test)을 시행하였으며 사후 검정으로 맨-휘트니 $\mathrm{U}$ 검정 (Mann Whitney U-test)을 시행하였다.

\section{III. 연구 성적}

\section{1. 표면미세경도(Surface microhardness)}

불소제제를 적용하여 재광화 한 후 시편의 표면미세경도를 측정하고 이를 이용하여 재광화율 $(\% \mathrm{SMR})$ 을 측정하였다. 재 광화율 $(\% \mathrm{SMR})$ 은 NaF-PVA군이 가장 높았으며 F-varnish 군, $\mathrm{CPP}-\mathrm{ACFP}$ 군, 대조군 순이었다. 모든 군에서 불소제제를 적용 이후 표면미세경도의 평균값의 차이는 유의하였다 $(p<$ 0.05 , Table 1). 각 그룹간에서 대조군은 NaF-PVA군과 Fvarnish군보다 유의하게 표면미세경도의 재광화율이 더 낮았 고, $\mathrm{NaF}-\mathrm{PVA}$ 군과 F-varnish군의 재광화율은 $\mathrm{CPP}-\mathrm{ACFP}$ 군 보다 유의하게 높았다 $(p<0.05)$. 대조군과 $\mathrm{CPP}-\mathrm{ACFP}$ 군과는 유의적인 차이를 보이지는 않았고 NaF-PVA군과 F-varnish 군 간에도 유의한 차이는 보이지 않았다( $p>0.05$, Table 2$)$.

\section{QLF의 $\Delta \mathrm{F}$ 값}

불소제제를 적용하여 재광화한 후 $\mathrm{QLF}$ 의 $\Delta \mathrm{F}$ 값이 다시 측 정되었다. 이 값을 이용하여 $\mathrm{QLF}$ 의 재광화율 $(\mathrm{R} \Delta \mathrm{F})$ 을 구하였 다. $\mathrm{QLF}$ 의 재광화율 $(\mathrm{R} \Delta \mathrm{F})$ 또한 표면미세경도 측정시와 마찬 가지로 $\mathrm{NaF}-\mathrm{PVA}$ 군이 가장 높았으며 F-varnish군, $\mathrm{CPP}-$ $\mathrm{ACFP}$ 군 순이었다. 탈회 후와 불소제제를 적용한 후의 각 그룹 별 시편의 $\Delta \mathrm{F}$ 값은 모든 그룹에서 유의한 차이를 보였다 $(p<$ 0.05, Table 3). 대조군은 다른 군들 (NaF-PVA군, F-varnish군 그리고 $\mathrm{CPP}-\mathrm{ACFP}$ 군)보다 유의하게 재광화율이 더 낮 았다 $(p<0.05)$. CPP-ACFP군은 NaF-PVA군과 F-varnish 군에 비해 유의하게 낮은 재광화율을 보였다 $(p<0.05) . \mathrm{NaF}^{-}$ PVA군은 F-varnish군에 비해 높은 재광화율을 보였지만 통계 적으로 유의하지는 않았다 $(p>0.05$, Table 4$)$.

\section{IV. 총괄 및 고찰}

본 실험에서 사용한 불소필름은 무색투명하며, 불쾌한 맛이 
Table 1. Recovery percentage of surface microhardness (\%SMR) of each group

\begin{tabular}{lccr}
\hline & \multicolumn{3}{c}{ KHN } \\
& KHN demineralization & KHN after treatment & \multicolumn{1}{c}{$\%$ SMR } \\
\hline control & $77.56 \pm 29.76$ & $84.91 \pm 32.98$ & $9.79 \pm 1.30^{*}$ \\
NaF-PVA & $77.81 \pm 18.93$ & $90.86 \pm 21.21$ & $16.18 \pm 1.72^{*}$ \\
F-varnish & $78.00 \pm 21.95$ & $90.64 \pm 25.44$ & $15.27 \pm 2.22^{*}$ \\
CPP-ACFP & $77.39 \pm 28.12$ & $86.79 \pm 31.61$ & $12.15 \pm 0.83^{*}$
\end{tabular}

Wilcoxon signed ranks test $(*: p<0.05)$

$\% \mathrm{SMR}=$ recovery percentage of surface microhardness, $\mathrm{KHN}=$ knoop Hardness Number, NaF-PVA = sodium fluoride-polyvinyl alcohol, F-varnish $=$ fluoride varnish, CPP-ACFP $=$ Casein phosphopeptide-amorphous calcium phosphate

Table 2. Comparison of the percentage of surface microhardness ( $\%$ SMR) among groups after treatment

\begin{tabular}{lcccc}
\hline & control & NaF-PVA & F-varnish & CPP-ACFP \\
\hline control & - & $\mathrm{S}$ & $\mathrm{S}$ & $\mathrm{S}$ \\
NaF-PVA & - & - & $\mathrm{N}$ & $\mathrm{S}$ \\
F-varnish & - & - & - & $\mathrm{S}$ \\
CPP-ACFP & - & - & - & -
\end{tabular}

Mann-Whitney U-tests $(* p<0.05)$

$\mathrm{S}$ : Significant difference between groups

$\mathrm{N}$ : Non-Significant difference between groups

없고 표면이 매끈하기 때문에 끈적거리는 느낌이 없다. 또한 사 용시에 치면을 건조시킬 필요가 없어 시술과정이 간편하여 집 에서 사용할 수 있는(Home care) 장점을 가지고 있다 ${ }^{12)}$. 불소 를 함유한 PVA 필름에 관한 이전의 논문들 ${ }^{12.13}$ 에서 그 효과가 입증되었지만, 표면미세경도 측정 등과 같은 정량화 할 수 있는 다른 입증법이 필요하였다. $\mathrm{QLF}$ 는 이 목적에 부합하는 장비로 현재 여러 문헌들에 의해 그 신뢰성이 높으며, 교합면 우식증의 경우 0.68 의 민감도와 0.70 의 특이도로 다른 진단 방법에 비해 높은 수준의 진단 능력을 갖기 때문에 $\mathrm{NaF}-\mathrm{PVA}$ 의 재광화 능 력을 측정하는데 사용하였다 ${ }^{17.19)}$.

소의 치아로 만든 시편의 탈회 전후 표면미세경도를 측정할 때의 문제점으로는 이전 측정 부위를 정확히 다시 재현할 수 없 다는 점과 측정자가 단 한사람이라는 점이었다. 이러한 문제점 을 최소화하고자 본 실험에서는 측정을 3 번 반복하여 평균값을 구하였다.

$\mathrm{QLF}$ 는 장비의 특성상 이전 촬영을 그대로 재현할 수 있다는 장점이 있다. 각 시편들의 탈회 이전의 Q-ray와 재광화 이후의 Q-ray는 99\%의 재현성으로 중첩(repositioning)되었다. 이런 높은 재현성으로 인해서 $\mathrm{QLF}$ 값의 변화로 얻어지는 재광화율 에 신뢰성을 부여하였다.

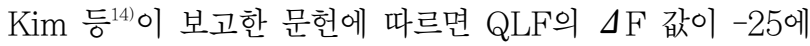
서 -15 사이일 때 임상가에게 불소도포를 권유하고 있으며 따 라서 본 실험에서도 초기 $\Delta \mathrm{F}$ 값을 -15 보다 더 낮은 값이 되도
Table 3. Recovery percentage of $\Delta \mathrm{F}(\%)$ of each group

\begin{tabular}{lccc}
\hline & \multicolumn{3}{c}{ QLF } \\
& QLF demineralization & QLF after treatment & $\mathrm{R}(\Delta \mathrm{F})$ \\
\hline control & $-25.53 \pm 4.60$ & $-22.67 \pm 4.56$ & $11.58 \pm 9.16^{*}$ \\
NaF-PVA & $-25.07 \pm 4.09$ & $-14.88 \pm 3.32$ & $40.35 \pm 9.67^{*}$ \\
F-varnish & $-23.13 \pm 3.67$ & $-14.45 \pm 3.63$ & $37.54 \pm 10.59^{*}$ \\
CPP-ACFP & $-24.93 \pm 4.45$ & $-19.37 \pm 3.03$ & $20.54 \pm 6.82^{*}$ \\
\hline
\end{tabular}

Wilcoxon signed ranks test $(*: p<0.05)$

$\mathrm{QLF}=$ quantitative light-induced fluorescence, $\mathrm{R}(\Delta \mathrm{F}):$ recovery percentage of $\Delta \mathrm{F}(\%)$

Table 4. Comparison of the recovery percentage of $\Delta \mathrm{F}(\%)$ among groups after treatment

\begin{tabular}{lcccc}
\hline & control & NaF-PVA & F-varnish & CPP-ACFP \\
\hline control & - & $\mathrm{S}$ & $\mathrm{S}$ & $\mathrm{S}$ \\
NaF-PVA & - & - & $\mathrm{N}$ & $\mathrm{S}$ \\
F-varnish & - & - & - & $\mathrm{S}$ \\
CPP-ACFP & - & - & - & - \\
\hline
\end{tabular}

Mann-Whitney U-tests $(* p<0.05)$

$\mathrm{S}$ : Significant difference between groups

$\mathrm{N}$ : Non-Significant difference between groups

록 하지만 너무 과하게 되지 않도록 탈회를 시행하였다. 그리하 여 시편들은 2 일동안 탈회가 진행되었다. 탈회가 끝나고 불소 제제의 적용 후 모든 군은 인공타액에 위치되었고 인공타액을 6시간마다 교체함으로써 실제 구강상태를 재현하고자 노력하였 다.

본 실험에서 시편들의 탈회 후와 불소제제 적용 후의 표면미 세경도의 측정결과 $\mathrm{NaF}-\mathrm{PVA}$ 필름이 대조군과 $\mathrm{CPP}-\mathrm{ACFP}$ 와 비교하여 유의하게 높은 재광화 효과를 보였다 $(p<0.05)$. Kim 등리이 시행한 NaF-PVA 필름을 이용한 법랑질의 탈회에 관한 실험실적 논문도 이와 비슷한 결과를 보고하였다. 소의 절 치로 만들어진 시편을 이용한 이 실험에서 $\mathrm{NaF}-\mathrm{PVA}$ 필름은 대조군과 $\mathrm{CPP}-\mathrm{ACFP}$ 에 비해 유의하게 탈회를 억제하는 능력 을 보였으며 이는 불소바니쉬인 FluoroDose ${ }^{\circledR}$ 와 견줄만하였다.

본 연구의 실험 결과에서 $\mathrm{CPP}-\mathrm{ACFP}$ 는 대조군 이외의 다른 두 군(NaF-PVA 필름군, F-varnish 군)과 비교시 표면미세경 도의 재광화율 그리고 $\mathrm{QLF}$ 의 $\Delta \mathrm{F}$ 값의 회복율이 유의하게 낮 게 나타났다. 이는 탈회 및 재광화 용액에 칼슘 이온과 인 이온 이 포함되어 있으므로 이로 인한 $\mathrm{CPP}-\mathrm{ACFP}$ 의 칼슘, 인 이온 의 공급효과가 부각되지 않을 수 있으며, $\mathrm{CPP}-\mathrm{ACFP}$ 가 불소 의 불화인회석의 형성에는 도움을 주지만 $\mathrm{CPP}-\mathrm{ACFP}$ 단독으 로는 이런 효과가 나타나지 않을 수도 있다는 Reynold 등의 의 보고와 일치하였다.

표면미세경도와 $\mathrm{QLF}$ 촬영을 이용한 이번 실험에서 결과의 
차이는 대조군과 $\mathrm{CPP}-\mathrm{ACFP}$ 군 사이에서 나타났다. 표면미세 경도의 재광화율은 비록 대조군이 더 낮았지만 대조군과 $\mathrm{CPP}-$ $\mathrm{ACFP}$ 군에서 유의적인 차이를 보이지 않았다 $(p>0.05)$. 하지 만 $\mathrm{QLF}$ 의 $\Delta \mathrm{F}$ 값의 재광화율은 $\mathrm{CPP}-\mathrm{ACFP}$ 군이 대조군보다 유의하게 높았다 $(p<0.05)$. 이는 $\mathrm{QLF}$ 시스템이 표면미세경도 측정보다 더 미세한 재광화율을 감지하기 때문이라고 생각된다.

$\mathrm{NaF}-\mathrm{PVA}$ 필름은 F-varnish에 비해 같은 부위에 사용하였 을 때 약 $35 \%$ 만의 불소량을 포함함에도 불구하고 $\mathrm{NaF}-\mathrm{PVA}$ 군과 F-varnish군 간의 재광화율은 유의한 차이가 발견되지 않 았다 ${ }^{12}$. NaF-PVA 필름이 이렇게 작은 불소의 함유량으로도 비슷한 효과를 발휘할 수 있는 이유는 이 제제의 지속적인 불소 방출능력 때문이다 ${ }^{13)}$. 불소의 지속적인 유리는 치아의 재광화에 중요한 역할을 하며 $\mathrm{NaF}-\mathrm{PVA}$ 필름의 이러한 능력은 이 제제 가 법랑질 재광화의 새로운 불소의 전달 매개체로 사용 될 수 있음을 보여준다 ${ }^{21,22)}$.

본 연구는 제제에 따른 법랑질의 재광화를 표면미세경도와 QLF를 이용하여 확인하고자 실험실 모형 상에서 구축된 실험 으로 일부 한계가 있었다. 우선 제제의 도포 횟수에서 군간 차 이가 있었다. 불소바니쉬 (FluoroDose ${ }^{\circledR}$ )는 3 6개월 재도포를 권장하고 있으나, $\mathrm{CPP}-\mathrm{ACFP}$ (Tooth mousse plus ${ }^{\mathrm{TM}}$ )의 경 우는 매일 2회 도포가 권장사항이다 ${ }^{23,24)}$. 이 실험에서 제조자의 지시사항을 지키려고 노력하였고 따라서 도포 횟수에 대한 차 이가 발생할 수밖에 없었다. 그리고 본 실험에서는 시편의 열순 환처리를 시행하지 않았으나 향후 보다 더 유사한 구강환경을 만들기 위해 열순환처리가 되어야하며 이와 함께 인공 칫솔질 도 고려되어야 한다. 하지만 칫솔질의 표준화가 이루어지지 않 으면 오차 발생의 가능성이 있어 조심스러운 접근이 필요할 것 으로 생각된다. 또한 본 연구는 2 일간의 탈회 그리고 7 일간의 재광화 기간이라는 단기간의 실험실적 논문이었다. 이는 장기 간 구내 환경을 동일하게 만들기 어려운 실험여건 때문이었다. 불소도포를 통한 재광화 실험에서 Lee 등ㄷ)은 제제 적용 4 주 후 측정시, 재광화 효과가 지속되었다고 보고하였으나 제제 적 용 2 주 후 회귀되는 양상을 보이는 실험 결과도 있었달) 따라 서 본 연구에서의 실험결과는 이러한 차이점들 때문에 장기간 측정시 각 제제간의 차이를 보이지 않을 수 있다는 점을 고려해 야 하며 향 후 장기간의 재광화 기간의 실험들이 더 필요할 것 으로 생각된다.

\section{V. 결 론}

이 연구는 표면미세경도와 $\mathrm{QLF}$ 를 이용하여 NaF-PVA 필름 의 재광화효과를 다른 불소제제들과 비교하기 위한 실험이다. 소의 절치를 이용하여 만든 시편 60 개를 탈회 후 임의로 대조 군, $\mathrm{NaF}-\mathrm{PVA}$ 군, $\mathrm{F}-\mathrm{varnish}$ 군, $\mathrm{CPP}-\mathrm{ACFP}$ 군 이렇게 4개의 군으로 나누어 제제를 적용하여 평가한 결과 다음과 같은 결론 을 얻었다.

표면미세경도와 $\mathrm{QLF}$ 의 $\Delta \mathrm{F}$ 의 재광화율은 $\mathrm{NaF}-\mathrm{PVA}$ 군, $\mathrm{F}-$ varnish군, $\mathrm{CPP}-\mathrm{ACFP}$ 군, 대조군 순이었다. 모든 군에서 제
제 적용 후 재광화율이 유의하게 증가하였다 $(p<0.05)$. 표면 미세경도 측정 결과, 대조군과 $\mathrm{CPP}-\mathrm{ACFP}$ 군은 $\mathrm{NaF}-\mathrm{PVA}$ 군 과 $\mathrm{F}-\mathrm{varnish}$ 군에 비해 유의하게 낮은 재광화율을 보였다 $(p<$ 0.05). 그러나 대조군과 $\mathrm{CPP}-\mathrm{ACFP}$ 군, 그리고 $\mathrm{NaF}-\mathrm{PVA}$ 군 과 $\mathrm{F}$-varnish군 간에는 유의한 차이를 보이지 않았다 $(p>$ 0.05). QLF $\Delta \mathrm{F}$ 의 재광화율은 대조군은 $\mathrm{NaF}-\mathrm{PVA}$ 군, $\mathrm{F}-$ varnish군, $\mathrm{CPP}-\mathrm{ACFP}$ 군에 비해 유의하게 낮았고 $\mathrm{NaF}-\mathrm{PVA}$ 군, $\mathrm{F}$-varnish군은 $\mathrm{CPP}-\mathrm{ACFP}$ 군에 비해 유의하게 높았다 $(p$ $<0.05)$. 그리고 $\mathrm{NaF}-\mathrm{PVA}$ 군과 $\mathrm{F}-\mathrm{varnish}$ 군은 유의한 차이 를 보이지 않았다 $(p>0.05)$.

\section{References}

1. Pretty IA : Caries detection and diagnosis: Novel technologies. J Dent, 34:727-739, 2006.

2. Pitts NB : Clinical diagnosis of dental caries: a European perspective. J Dent Educ, 65:972-978, 2001.

3. Angmar-Månsson B, ten Bosch JJ : Advances in methods for diagnosing coronal caries - a review. Adv Dent Res, 7:70-79, 1993.

4. Lee SH, Lee NY : A study of the caries activity test with visible light induced by laser. $J$ Korean Pediatr Dent, 27:161-168, 2000.

5. Levine RS : Remineralization of natural carious lesion on enamel in vitro. Br Dent J, 137:132-141, 1974.

6. Salar DV, García-Godoy F, Flaitz CM, et al. : Potential inhibition of demineralization in vitro by fluoride-releasing sealants. J Am Dent Assoc, 138: 502-506, 2007.

7. Kim JB, Paik DI, Moon HS et al. : Clinical preventive dentistry. 4th ed. Seoul:Komoonsa:277-282, 2009.

8. Adair SM : Current fluoride therapy in dentistry for children. Curr Opin Dent, 1:583-591, 1991.

9. Toumba KJ, Curzon ME : A clinical trial of a slowreleasing fluoride device in children. Caries Res, 39:195-200, 2005.

10. Marini I, Checchi L, Vecchiet F, Spiazzi L : Intraoral fluoride releasing device: a new clinical therapy for dentine sensitivity. J Periodontol, 71:9095, 2000.

11. Fusako K, Xiaoping H : Biochemistry of microbial polyvinyl alcohol degradation. Appl Microbiol Biotechnol, 84:227-237, 2009.

12. Kim MJ, Lee SH, Lee NY, Lee IH : Evaluation of the effect of PVA tape supplemented with $2.26 \%$ flu- 
oride on enamel demineralization using microhardness assessment and scanning electron microscopy: In vitro study. Arch Oral Biol, 58:160-166, 2013.

13. Lee KY, Lee SH, Lee NY : Evaluation of fluoridereleasing capacity from polyvinyl alcohol polymer tape supplemented with $\mathrm{NaF}$ in oral cavity. $J$ Korean Acad Pediatr Dent, 40:89-97, 2013.

14. Kim HE, Kwon HK, Kim BI : Recovery percentage of remineralization according to severity of early caries. Am J Dent, 26:132-136, 2013.

15. Grewal N, Kudupudi V, Grewal S : Surface remineralization potential of casein phosphopeptide-amorphous calcium phosphate on enamel eroded by coladrinks: An in-situ model study. Contemp Clin Dent, 4:331-7, 2013.

16. Vahid Golpayegani M, Sohrabi A, Biria M, Ansari G : Remineralization Effect of Topical NovaMin Versus Sodium Fluoride (1.1\%) on Caries-Like Lesions in Permanent Teeth. J Dent (Tehran), 9:68-75, 2012.

17. Pretty IA : A review of the effectiveness of QLF to detect early caries lesions. Indianapolis, Indiana: Indiana University Press; 2005.

18. Cheng L, Ten cate JM : Effect of Galla chinensis on the in vitro Remineralization of advanced enamel lesions. Int J Oral Sci, 2:15-20, 2010.

19. Stookey GK : Quantitative light fluorescence: a technology for early monitoring of the caries process.
Dent Clin North Am, 49:753-770, 2005.

20. Reynolds EC, Cai F, Reynolds C : Fluoride and casein phosphopeptide-amorphous calcium phosphate. J Dent Res, 87:344-348, 2008.

21. White DJ, Nelson DGA, Faller RV : Mode of action of fluoride: application of new techniques and test methods to the examination of the mechanism of action of topical fluoride. Adv Dent Res, 8:166-174, 1994.

22. Øgaard B, Seppä L, Rolla G : Professional topical fluoride applications -clinical efficacy and mechanism of action. Adv Dent Res, 8:190-201, 1994.

23. Jayarajan J, Janardhanam P, Jayakumar P : Efficacy of CPP-ACP and CPP-ACPF on enamel remineralization - an in vitro study using scanning electron microscope and DIAGNOdent. Indian $J$ Dent Res, 22:77-82, 2011.

24. American Dental Association : Council on Scientific Affairs: Professionally applied topical fluoride. J Am Dent Assoc, 137:1151-1159, 2006.

25. Lee YE, Beak HJ, Jeong SH, et al. : A comparison of the effectiveness of three different fluoride regimens in increasing the acid resistance of enamel. $J$ Korean Acad Oral Health, 33:19-29, 2009.

26. Lee MS, Park DY, Ma DS : The remineralization effect of topical fluoride agents on artificial enamel caries. J Korean Acad Oral Health, 36:85-90, 2012. 
국문초록

\title{
$5 \%$ 불화나트륨을 함유한 고분자 접착필름의 법랑질 재광화효과
}

\author{
지명관 · 이상호 · 이난영 \\ 조선대학교 치의학전문대학원 소아치과학교실
}

이 논문은 법랑질의 표면미세경도와 $\mathrm{QLF}$ 의 $\Delta \mathrm{F}$ 값의 변화를 분석하여 $5 \%$ 불화나트륨을 함유한 고분자 접착 테잎 $\left(\mathrm{NaF}^{-}\right.$ $\mathrm{PVA}$ )이 법랑질의 재광화에 미치는 영향을 평가하고자하였다.

시편을 탈회한 후 표면미세경도가 평균 50-100 KHN의 범위를 갖고 $\mathrm{QLF}$ 의 $\Delta \mathrm{F}$ 값이 -25에서 -15 범위를 갖는 60개의 시편들을 4그륩으로 나누었다 : 그룹1(대조군), 그륩2(NaF-PVA), 그룹3(불소바니쉬, FluoroDose ${ }^{\circledR}$ varnish), 그룹 4(Casein phosphopeptide-amorphous calcium phosphate, Tooth mousse plus ${ }^{\mathrm{TM}}$ ). 시편들에 각 제제들을 적용하고 인 공타액 (artificial saliva)에 담근 후 표면미세경도계와 정량 광 형광기를 이용하여 재광화율을 측정하였다.

그 결과 불소를 함유한 고분자 접착 테잎 $(\mathrm{NaF}-\mathrm{PVA})$ 은 그룹1과 4 보다 뛰어나며 그룹3과 견줄만한 재광화 효과를 나타냈 다 $(p<0.05)$.

주요어: 불화나트륨을 함유한 고분자 접착 테잎, 재광화, 정량 광 형광기 